\title{
EEN EERSTELING: MET GEJUICH BEGROET?
}

\author{
door J. A. Burggraaff
}

Op 20 januari 1977 wees de Ondernemingskamer van het Gerechtshof te Am. sterdam (OK) haar eerste arrest aangaande de inhoud van een jaarrekening. Op vordering van enkele aandeelhouders gaf zij aan de bestuurders van Douwe Eg. berts B.V. (DE) bevel om bij het opmaken van toekomstige jaarrekeningen bepaalde, door de OK gespecificeerde, aanwijzingen in acht te nemen.

Dit arrest zal te zijner tijd in extenso worden gepubliceerd in Nederlandse Jurisprudentie. In TVVS, maart 1977, is het bevel van de OK, met enkele van de overwegingen, weergegeven; De Accountant, april 1977, bevat een resumé van de uitspraak. Het lijkt van belang ook in het MAB enkele punten naar aanleiding van dit arrest te bespreken; van een volledige weergave annex bespreking mor worden afgezien.

\section{Welke normen worden in het maatschappelijk verkeer als aanvaardbaar beschouwd?}

Eisers baseerden hun vordering tot herziening van de in geding zijnde jaarreke. ning 1974 voor een deel op bezwaren tegen de door DE toegepaste grondslagen voor waardering en resultaatbepaling. Zoals bekend worden in de Wet Jaarreke. ning Ondernemingen (WJO)') behoudens een enkele uitzondering geen specifieke waarderingsvoorschriften gegeven: de wetgever heeft de vraag wat aanvaardbaar is en wat niet aan het maatschappelijk verkeer ter beoordeling overgelaten ${ }^{2}$.

Bij de parlementaire behandeling van het ontwerp.WJO heeft de minister de verwachting ${ }^{3}$ ) uitgesproken, dat bedrijfsleven en accountants hier een taak voor zich zouden zien. De organisaties van werkgevers, werknemers en registeraccountants hebben, tot verheugenis ${ }^{4}$ ) van de minister, op deze wenk gereageerd, en hun commissies jaarverslaggeving, gewoonlijk aangeduid als het Tripartiete Overleg (TO) hebben zich gezet aan de taak van inventarisatie en toetsing. De uitkomsten van hun arbeid worden gepubliceerd als Beschouwingen, waarvan tot dusver 5 afleveringen verschenen; 2 in definitieve versie en 3 als voorontwerp. Het TO is zich steeds bewust geweest van de beperkte gelding die zijn Beschouwingen hebben. De deskundigheid van de TO-deelnemers, de grondigheid van hun onder. zoek, het gewicht van hun achterban mogen aan de Beschouwingen enig, en wel. licht een groot gezag geven, het laatste woord is niet aan het TO doch aan de rechter, i.c. de $\mathrm{OK}^{5}$ ). Desondanks mochten de deelnemers de door de minister ${ }^{6}$ )

\footnotetext{
1) Deze wet is inmiddels in het Burgerlijk Wetboek opgenomen als Boek 2 titel 6. In dit artikel wordt nog verwezen naar de notatie in de WJO.

2) Art 5, lid 1 WJO: de grondslagen waarop de waardering van de aciva en de passiva en de bepaling van het resultaat be. rusten, voldoen aan normen die in het maatschappelijk verkeer als aanvaardbaar worden beschouwd.

3) MvT, pag 14 l.k.: De ondergetekende verwacht dat her georganiseerd bedrijfsleven en in samenwerking daarmede de or ganisatie der accountants het tot hun taak zullen rekenen de in het maatschappelijk verkeer gehanteerde grondslagen als in ar tikel 5 bedoeld te inventariseren en te toetsen aan hetgeen naar hun oordeel in het huidige bestel in het maatschappelijk verkeer en ter voldoening aan de eisen van de artikelen 2 en 3 als aanvaardbaar kan worden beschouwd.

4) MvA pag. 6 l.k; En passant werd ( $\mathrm{MvA}_{1}$ pag. 10, r.k) aan het TO ook nog een taak toegedacht met betrekking tot de in art. 29. lid I WJO geëiste nadere splitsing en toelichring van het bedrijfsresultaat volgens voor de betrokken bedrijfstak aanvaard bare maatstaven.

5) Zie een artikel van de eerste TO voorzitter Prof. A. M. van Rietschoten, Weerzien van een voorontwerp. MAB 1974, pag. 268.

Y MvT pag. 14 l.k: De hieruit voortvloeiende publicaties omtrent aanvaardbare grondslagen zullen .... mede ter oriëntatie van het Gerechishof te Amsterdam kunnen dienen, wanneer een geschil terzake aan haar oordeel wordt voorgelegd.
} 
gewekte hoop koesteren, dat hun Beschouwingen bij de OK enig gewicht zouden hebben. Welnu, daarvan is in het onderhavige geding niet gebleken.

Het is aannemelijk dat partijen in het geding, zo dit hun te stade kwam, zich op de Beschouwingen hebben beroepen. De sporen daarvan zijn hier en daar, n.l. waar de argumenten van partijen worden weergegeven, in het arrest aan te wij. zen. Iedere expliciete verwijzing naar die Beschouwingen ontbreekt evenwel. Voor de OK, zo moet uit althans dit arrest worden geconcludeerd, is het TO te onbelangrijk om er een woord aan te spenderen.

Dit is betreurenswaardig, en wel om twee redenen.

1. Voorzover de OK in haar arrest afwijkt van de Beschouwingen is onzekerheid geschapen, of zij de opvatting van het TO ten principale afwijst, dan wel of zij, die opvatting weliswaar in haar algemeenheid onderschrijvend, haar uitsluitend in de specifieke omstandigheden van de casus-DE niet toepasselijk acht. Uiteraard, de OK heeft alleen te oordelen in het haar voorgelegde geschil, derhalve casuïstisch. Dit neemt niet weg dat m.i. van de OK een uitspraak in zodanige bewoordingen zou mogen worden verwacht, dat enige klaarheid wordt bevorderd aangaande de in het algemeen aanvaardbaar te achten gedragslijn.

2. Zo dit arrest mocht worden gevolgd door andere waarin eveneens stilzwij. gend aan de Beschouwingen wordt voorbijgegaan, zal het materieel gezag van die Beschouwingen ernstig worden aangetast. Wanneer aan verantwoor. dingsplichtigen geen uitingen met enig gezag kunnen worden voorgehouden, zal dit een ongunstig effect hebben op de kwaliteit van de verslaggeving van ondernemingen. Het zou geen goede zaak zijn, wanneer het werk van gezel. schappen die nationaal en internationaal tot precisering van normen pogen te komen, door de rechter zou worden genegeerd, en daardoor krachteloos gemaakt.

\section{Lopende in- en verkoopcontracten}

Eisers ${ }^{7}$ ) verlangden vermelding van lopende inkoop. en vaste verkoopcontracten, alsmede uiteenzetting van de toegepaste waarderingsgrondslagen. $\mathrm{DE}^{8}$ ) zag het nut daarvan niet in. De $\mathrm{OK}^{9}$ ) besloot tot de volgende aanwijzing: ,de jaarrekening dient naast de vermelding van de uit lopende in en verkoopcontracten van

\footnotetext{
${ }^{7}$ ) Stellingen van eisers (geparafraseerd; JAB);

- produkten als koffie en thee zijn objecten van termijnhandel;

- indien daarop geen vaste verkoopcontracten zijn gesloten, dient zulks in de toelichting te worden vermeld;

- uit de jaarrekening blijkt niet op welke wijze prijsdalingen op lopende inkoopcontracten van grondstoffen worden verwerkt;

- ten onrechte is niet vermeld welke verplichingen uit lopende inkoop contracten voort vloeien, en hoe deze verplichingen wor den gewaardeerd.

o) Stellingen van DE (geparafraseerd; JAB):

- vermelding van het feit dat geen vaste verkoopcontracten zijn gesloten behoeft niet plaats te vinden;

- vermelding van lopende inkoopcontracten van grondstoffen mag achterwege blijven aangezien vermelding daarvan naast de in de balans opgenomen technische voorraad geen beter inzicht geeft;

- de omvang van de contractpositie vloeit voort uit de normale bedrijfsvoering en maakt ca. 10\% van het grondstoffenverbruik uit;

- verliezen op lopende inkoopcontracten worden direct als verlies genomen;

- nu geen verliezen te verwachten zijn, is daarvan terecht geen melding gemaakt en behoeft daarvoor geen voorziening te wor. den getroffen.

9) Overweging van de OK: de ondernemingskamer is van oordeel dat voor een ondememing als DE, waarin de voor de grondstoffen te betalen prijzen een zo overwegend deel van de kostprijs van het gereed produkt vitmaken en in zo belangrijke mate het resultaat bepalen en waarin derhalve aan de contractpositie een grote betekenis toekomt, de onderhavige jaarrekening, waarin uitsluitend de technische voorraad en de daarvoor toegepaste waarderingsgrondslag is vermeld, onvoldoende informatie verschaft zowel ter beoordeling van haar vermogen en solvabiliteit als van haar resultaat.
} 
grondstoffen voortvloeiende rechten en verplichtingen een uiteenzetting te geven omtrent de voor deze grondstoffen toegepaste waarderingsmaatstaf en de eventuele invloed daarvan op het resultaat".

Het is van belang op te merken, dat blijkens de structuur van het arrest de OK de klacht van eisers niet in verband brengt met art. 25, lid I WJO (vermelding van niet in de balans opgenomen financiële verplichtingen die naar hun aard of omvang van bijzondere betekenis zijn), doch beoordeelt in het kader van art. 5 WJO, handelend over de grondslagen van waardering en resultaatbepaling en hun uiteenzetting. $\mathrm{Zjj}$ concludeert, dat met betrekking tot grondstoffen niet kan worden volstaan met vermelding van de technische voorraad. $\mathrm{Zij}$ gaat echter niet zover, dat zij vermelding van de economische voorraad verlangt; zoals nader zal blijken wordt dit gegeven door de aanwijzing niet aan het licht gebracht.

Over de keuze economische versus technische voorraad heeft het TO zich ge. uit $^{10}$ ) in de zin dat opneming van de technische voorraad in de balans gebruikelijk is; opneming van de economische voorraad wordt toelaatbaar geacht maar niet bepleit. Elders ${ }^{11}$ ) wordt opneming van de economische voorraad, in samenhang met waardering tegen opbrengstprijzen, niet ongebruikelijk genoemd voor be. paalde bedrijfstakken.

Lopende in en verkoopcontracten komen, aldus het $\mathrm{TO}^{12}$ ), alleen voor vermel. ding in aanmerking wanneer zij abnormaal omvangrijk zijn.

In het Commentaar op de WJO onder redactie van Sanders en Burgert wordt voorkeur ${ }^{13}$ ) uitgesproken voor opneming van de economische voorraad, en onder omstandigheden zelfs een grote voorkeur.

Voor wat betreft de vermelding van lopende in - en verkoopcontracten volstaat het Commentaar met verwijzing naar de Memorie van Toelichting ${ }^{14}$ ).

IJsselmuiden roert in zijn Wet op de Jaarrekening de onderhavige problematiek niet aan.

Ongetwijfeld heeft vermelding van de economische voorraad, naast de technische, informatieve waarde: dit gegeven stelt in staat te beoordelen in welke mate prijsbewegingen van invloed zijn c.q. kunnen zijn op de uitkomsten van het ondernemen. Desondanks wordt de economische voorraad in de jaarrekening veelal niet aangetroffen, hetgeen o.m. te maken heeft met de volgende omstandigheden:

- het betreft gevoelige informatie: hoogst belangwekkend voor de concurrenten, vooral wanneer hun aantal beperkt is;

- het betreft manipuleerbare informatie: door contractsluiting resp. rescontrering

\footnotetext{
10) Beschouwingen hoofdstuk II b 1, alinea 6: Het is gebnuikelijk in de balans de technische voorraad te vermelden. Is niet de technische, maar de economische voorraad in de balans opgenomen, dan dient hiervan in de toelichting melding te worden gemaakt.

I) Beschouwingen hoofdstuk II b 1, alinea 31: Eenzelfde gedragslijn (n.l. waardering tegen opbrengstwaarde) is niet onge bruikelijk in de handel in agrarische, dierlijke of minerale produkten... Vaak gaat het hier om marktposities, mede omvattende de in en verkoopcontracten (economische voorraad).

12) Beschouwingen hoofdstuk $V$ b, alinea 17: Verplichtingen uit in- en verkoopcontracten betrekking hebbend op voorraden zijn naar hun omvang van bijzondere betekenis indien zij in verhouding tor de normale bedrijfsomvang een abnormaal grote afname of leveringspliche inhouden.

${ }^{13}$ ) Wet op de Jaarrekening van Ondernemingen; onder redactie van Prof. Mr P. Sanders en Prof. Drs. R. Burgert; Samsom Uitgeverij; losbladige editie. Toelichting III, art 16.3: Hoewel tb.v. een juiste winstbepaling het opvoeren van de economische voorraad de voorkeur verdient, geschiedt dat in de praktijk veelal niet. Daartegen behoeft geen overwegend bezwaar te bestaan, wanneer rekening wordt gehouden met eventuele verliezen op contractposities. Voor ondememingen die te maken hebben met goederen waarin een termijnmarkt bestaat, moet echter een grote voorkeur voor het opnemen van de economische voorraad uitgesproken worden. Ook voor ondememingen waarvoor de contractposities in verhouding tot de technische voorraad zeer belangrijk zijn.

14) MvT pag. 19 r.k: , zodat blijkt dat b.v. niet gedacht is aan bestellingen in de normale uitoefening van het bedrijf
} 
voor resp. na balansdatum kan een positie worden geconstrueerd en getoond die de ondernemingsleiding convenieert;

- het is in vele bedrijfstakken geen harde informatie: alle gradaties zijn bij in. en verkoopcontracten mogelijk met als ene uiterste het bindende, gespecificeerde contract, en als andere uiterste de globale, nog nader in te vullen, letter of in. tent.

Naar blijkt heeft DE zich gedragen naar de opvatting van het TO, en heeft zij de grote voorkeur van het Commentaar niet gevolgd. De OK lijkt, in de casus.DE, nog een stap verder te gaan door als verplicht aan te merken datgene wat bij het Commentaar slechts „grote voorkeur” had. De door de OK gegeven aanwijzing resulteert echter niet in opneming van de economische voorraad in de balans. $\mathrm{Bij}$ een verwerkende industrie wordt de economische voorraad in een grondstof immers niet alleen bepaald door de positie in die grondstof als zodanig, maar mede door de positie in de produkten waarin de grondstof wordt verwerkt. Het produktieproces is daar als het ware de sluis waardoor verschillende markten, en daarmede de posities in die markten, met elkaar in verbinding staan. Zo de OK bedoelde te eisen dat de economische voorraad moet worden vermeld, dan had zij in haar aanwijzing niet alleen de positie in grondstoffen maar tevens die in produkten moeten begrijpen.

Als de OK dan niet beveelt de economische voorraad te vermelden, wat heeft haar dan bewogen om, met voorbijgaan van de argumenten van $\mathrm{DE}$, toch vermelding van de contractpositie in grondstoffen te eisen? Haar overweging ${ }^{9}$ ) blijkt te zijn:

- de grondstof-quote in de kostprijs is hoog;

- dus is de grondstofprijs in belangrijke mate bepalend voor het resultaat;

- dus komt aan de contractpositie grote betekenis toe ter beoordeling van vermogen, solvabiliteit en resultaat.

Deze gedachtengang van de OK kan ik moeilijk volgen. Dat de contractpositie voor de beoordeling van vermogen en solvabiliteit betekenis kan hebben - ook al is die positie als gezegd manipuleerbaar - is duidelijk, maar dan blijven toch de vragen:

- waarom alleen de positie in grondstoffen, en niet die in produkten moet worden medegedeeld;

- waarom aan die positie betekenis, zelfs grote betekenis moet worden gehecht indien zij aequivalent is aan slechts 5 weken produktie.

Dat de contractpositie voor de beoordeling van het resultaat betekenis kan hebben is minder duidelijk. Die betekenis zou er wèl zijn, indien aan DE zou zijn be. volen om, naast de verwerking van ongerealiseerde verliezen, ook mededeling te doen van ongerealiseerde winsten op contractposities. Dit stukje informatie wordt door de aanwijzing van de OK echter niet op tafel gebracht. Die betekenis zou er eveneens zijn, indien de OK mededeling van de totale contractpositie, en dus van de economische voorraad had bevolen: de lezer van de jaarrekening zou dan kunnen beoordelen in welke mate de onderneming aan eventuele prijsfluctuaties is blootgesteld.

Ik ben geneigd te veronderstellen dat de OK, nu eisers zich alleen beklaagden over het ontbreken van informatie over de grondstoffencontracten, niet buiten het geschil van partijen heeft willen treden, en haar aanwijzing daarom tot de grondstoffen heeft beperkt. Zo eisers ook de produktencontracten in hun klacht 
hadden betrokken ${ }^{15}$ ), zou de OK genoopt zijn geweest zich duidelijk uit te spreken aangaande het wezenlijke vraagstuk, t.w. technische voorraad versus economische voorraad. De overweging van de OK (technische voorraad alleen geeft onvoldoende informatie) maakt plausibel dat zij dan vermoedelijk vermelding van de economische voorraad zou hebben voorgeschreven.

Die eis zou dan naar analogie van toepassing zijn voor alle gevallen waarin:

- de onderneming een relatief hoge grondstof-quote in haar kostprijs heeft; en

- die grondstoffen op wereldmarkten worden verhandeld, zodat wereldmarkt. prijzen worden genoteerd; terwijl

- bindende aan-en/of verkoopcontracten voor levering op termijn usantieel of althans mogelijk zijn.

Moet het arrest van de OK inderdaad zó worden geïnterpreteerd? Het lijkt gewenst dat het TO zich daarover eens buigt.

\section{Posten van te verwaarlozen betekenis}

Art. $4 \mathrm{WJO}^{16}$ ) laat ruimte aan bepaalde detailleringsvoorschriften geen gevolg te geven, indien dit zou leiden tot afzonderlijke vermelding van posten die in het geheel van de jaarrekening van te verwaarlozen betekenis zijn. Deze bepaling werd door $\mathrm{DE}$ in het geding gebracht naar aanleiding van de klacht van eisers, dat de post Overige Voorzieningen ten bedrage van 13,6 mln niet gespecificeerd was. Dit bij een geconsolideerde balanstelling van $686 \mathrm{mln}$, en een totaal aan voorzieningen in de balans van $59 \mathrm{mln}$.

Bedoelde bepaling had ook kunnen worden betrokken - in feite blijkt niet uit het arrest dat dit inderdaad geschied is - op een andere klacht van eisers, n.l. dat van de mutaties in niet-geconsolideerde deelnemingen (balanswaarde $7 \mathrm{mln}$ ) al. leen die ten gevolge van resultaten $(18 \mathrm{~m})$ was medegedeeld, terwijl van de overige wijzigingen (minus $485 \mathrm{~m}$ ) geen specificatie was gegeven.

Het TO heeft zich over de criteria van "materiality” geuit ${ }^{17}$ ): afzonderlijke vermelding is noodzakelijk indien een balanspost méér uitmaakt dan $5 \%$ van de balanstelling of $10 \%$ van het rubriektotaal. Deze uiting is opgenomen in een voorontwerp-Beschouwing dat in juni 1975 verscheen. Bij de opstelling van de onderhavige jaarrekening van DE in april 1975 kon met dat voorontwerp nog geen re. kening zijn gehouden, terwijl nog moet worden afgewacht, of het TO in de definitieve versie de geopperde criteria ongewijzigd zal handhaven.

In Commentaar en IJsselmuiden wordt niet concreet ingegaan op de vraag, wanneer een post van te verwaarlozen betekenis is.

Wat de Overige Voorzieningen betreft, bij verhoor van de accountant bleek dat hierin een twintigtal posten waren begrepen, dat de grootste nog geen $5 \mathrm{mln}$ be-

\footnotetext{
15. Het is mogelijk, dat eisers, resp. de OK uit de gedingstukken hebben gecondudeerd, dat er geen verkoopcontracten voor produkten liepen. Uit het arrest blijkt dit niet: daar is uitsluitend sprake van vaste verkoopcontracten op de termijnmarkt, en die kunnen alleen grondstoffen, niet produkten betreffen.

16. Art. 4 WJO,2e volzin: Daarbij worden in ieder geval de voorschriften, vervat in de hoofdstukken II en II, in acht genomen tenzij dit zou leiden tot afzonderlijke vermelding van posten die in het geheel van de jaarrekening van te verwaarlozen betekenis zijn.

17) Voorontwerp Beschouwingen hoofdstuk 1 b 1 , alinea 5: Het is voor het inzicht in de samenstelling van het vermogen noodzakelijk dat in de balans of in de toelichting afzonderlijk wordt vermeld elke in hoofdsnk Il WJO genoemde post waaran het bedrag méér uitmaakt dan $5 \%$ van de balanstelling of $10 \%$ van het bedrag van de in hoofdstuk II WJO vermelde rubriek van activa en passiva waartoe (de) desbetreffende post behoort. Bedraagt het totaalbedrag van de rubriek minder dan $5 \%$ van de balanstelling dan is afzonderlijke vermelding van de rubriek voor het inzicht niet van belang.
} 
liep, zodat elke post minder is dan $10 \%$ van het totaal van de voorzieningen. De door DE gevolgde gedragslijn was derhalve geheel in overeenstemming met het TO. De $\mathrm{OK}^{18}$ ) gaf impliciet te kennen, de criteria van het TO niet geheel te onderschrijven: niet alleen de niet-gespecificeerde post moet van te verwaarlozen betekenis zijn, ook de som der niet-gespecificeerde posten moet in verhouding tot het rubriektotaal onbelangrijk zijn. Voorts oordeelde zij dat het achterwege laten van afzonderlijke vermelding niet ontslaat van de verplichting inzicht te geven in aard en omvang van de risico's en verplichtingen waartegen voorzieningen zijn gevormd. En haar bevel bevatte dan ook de aanwijzing:

"In de jaarrekening dienen de niet in lid 2 van artikel 23 WJO (artikel 329 Boek $2 \mathrm{BW}$ ) bedoelde voorzieningen te worden gesplitst overeenkomstig het in lid 1 van dat artikel bepaalde. Voor zover zulks zou leiden tot vermelding van posten welke in het geheel van de jaarrekening van te verwaarlozen betekenis zijn, dient inzicht te worden gegeven in aard en omvang van de risico's en verplichtingen waartegen deze voorzieningen zijn gevormd in voege als hiervóór (zie noot 18; JAB) overwogen".

Wat de niet-geconsolideerde deelnemingen betreft had DE gesteld dat art. 12 lid $2 \mathrm{WJO}$ alleen inlichtingen omtrent de waardewijziging ten gevolge van resul. taten eist, en dat van de overige wijzigingen geen specificatie werd verlangd. Dit verweer was niet gelukkig gekozen, omdat werd voorbijgegaan aan art. 12, lid 1 WJO dat inlichtingen vraagt omtrent wijzigingen in de waarde van deelnemin gen. Wie voldoet aan art. 12 lid 2 heeft nog niet automatisch voldaan aan art. 12 lid 1. Zulks kan ook worden afgeleid uit de Beschouwingen ${ }^{19}$ ). Nu DE geen be roep deed op art. $4 \mathrm{WJO}$ bevat het bevel van de OK geen verrassing. Het luidde:

„De inlichtingen omtrent de wijziging van de waarde van niet-geconsolideerde deelnemingen, anders dan voortvloeiende uit de resultaten, dienen voor de ge zamenlijke deelnemingen afzonderlijk te vermelden de uit eenzelfde oorzaak (per saldo) voortvloeiende wijzigingen."

Overzie ik deze beide bevelen tezamen, dan meen ik dat zij een algemene strek. king hebben, en derhalve niet beperkt zijn tot de specifieke omstandigheden waarin DE verkeert. Die strekking zou ik als volgt willen weergeven:

1. Als criterium voor het niet afzonderlijk vermelden van een post geldt niet al leen de relatieve grootte van die post, maar tevens de relatieve grootte van de som der niet-gespecificeerde posten onder een rubriek.

2. Zo posten niet gespecificeerd zijn, kan niet volstaan worden met de omschrij. ving „,overige”, maar dient inzicht te worden gegeven in de aard der daaron.

\footnotetext{
18) Overweging van de OK: Dit laatste wettigt echter naar het oordeel van de Ondernemingskamer niet de conclusie dat de splitsing, die artikel 29, lid 1, WJO voor de hier bedoelde „overige” voorzieningen uitdrukkelijk voorschrijft, geheel als DE heeft gedaan, achterwege mag blijven. Voor het inzicht dat de jaarrekening krachtens artikel 2 WJO beoogt te geven is inzicht in aard en omvang van de risico's en verplichtingen waartegen de voorzieningen zijn gevormd van groot belang. Zulks brengt met zich. dat indien de door de wetgever voorgeschreven splitsing van de „overige" voorzieningen zou leiden tot afzonderlijke vermelding van posten, welke in het geheel van de jaarrekening van te verwaarlozen betekenis zijn, wel ingevolge arrikel $4 \mathrm{WJO}$ de afzon derlijke vermelding van deze posten achterwege mag blijven, doch niet dat daarin geen inzicht zou dienen te worden gegeven. Zulks geldt in het bijzonder in het onderhavige geval, waarin het totale bedrag van de hier bedoelde voorzieningen in verhouding tot het totale bedrag der voorzieningen als niet onbelangrijk is aan te merken. Het opnemen in de toelichting op de jaarrekening van een mededeling als vermeld, onder vermelding tevens van de aard van de belangrijkste risico's en verplichtingen waartegen de voorzieningen zijn gevormd, moet voor het te verschaffen inzicht noodzakelijk worden geacht en behoeft niet te leiden tor vermelding van posten waarvan de afzonderlijke vermelding als van te verwaarlozen betekenis achterwege mag blijven.

19) Beschouwingen hoofdstuk lla 3, alinea 27: Voorts verlangt de wet dat voor de deelnemingen inlichtingen worden verstrekt over de in het afgelopen boekjaar opgetreden wijzigingen in de (intrinsieke) waarde. Deze wijzigingen kunnen o.m. uit de vol. gende elementen bestaan: etc.
} 
der begrepen posten. Dit zou mutatis mutandis eveneens kunnen gelden voor overzichten, waarin de mutaties in bepaalde actief- of passiefposten worden gespecificeerd.

\section{Inlichtingen over de post vaste activa}

In de jaarrekening van $\mathrm{DE}$ was op de boekwaarde der vaste activa tweeërlei specificatie gegeven:

a. Vervangingswaarde c.q. aanschaffingskosten - geaccumuleerde afschrijvingen - boekwaarde; in totalen.

b. Splitsing van de boekwaarde in terreinen - bedrijfsgebouwen - machines inventarissen en vervoermiddelen - in bestelling/aanbouw.

Uit de Staat Herkomst en Besteding van Middelen was het totaalbedrag der in. vesteringen af te lezen, terwijl men in de winst-en verliesrekening het totaal der jaarafschrijvingen kon vinden.

In de toelichting was vermeld, dat gebouwen en machines tegen vervangingswaarde, de overige vaste activa tegen aanschaffingskosten waren gewaardeerd, onder aftrek van afschrijvingen op basis van de geschatte economische levens. duur.

Eisers beklaagden zich dat onduidelijk is hoe de afschrijvingen werden bere kend, en vonden dat de economische levensduur, toegekend aan de verschillende groepen activa, moest worden vermeld. DE vond dat veel te ver gaan, en ook onpraktisch: binnen de groepen deden zich immers per object ook nog verschillende levensduren voor.

Het TO deed in mei 1976 een aanbeveling ${ }^{20}$ ) aangaande de bijzonderheden be treffende de vaste activa die voor vermelding in aanmerking komen. Blijkens een in beperkte kring verspreide toelichting achtte het TO een ruimere informatie met betrekking tot toegepaste waarderings- en afschrijvingsgrondslagen gewenst; vermelding van geschatte levensduren zou van betekenis kunnen zijn, maar in het algemeen geen overzichtelijk resultaat geven. Vandaar dat het TO vermelding van geaccumuleerde cijfers per groep aanbeval.

In het Commentaar wordt, op grond van de parlementaire behandeling van het ontwerp WJO, geconcludeerd ${ }^{21}$ ), dat aan de WJO wordt voldaan door vermel. ding van de boekwaarde, en dat geen verplichting bestaat „hoofdsom” en geac. cumuleerde afschrijving mede te delen. Door de auteurs wordt het ontbreken van die verplichting betreurd ${ }^{22}$ ). IJsselmuiden acht, mede gezien het gebruik in binnen- en buitenland, die verplichting wèl aanwezig. ${ }^{23}$ )

De OK was het eens met eisers, dat $\mathrm{DE}$ in haar jaarrekening de voor vaste activa toegepaste grondslagen onvoldoende had uiteengezet. Zij verplichtte DE echter

\footnotetext{
20) Beschouwingen hoofdstuk II al, alinea 22: Als onderdeel van deze uiteenzetting (van de toegepaste waarderingsgrond slagen) is een overzicht van geaccumuleerde cijfers per groep van vaste activa aanbevelenswaardig. In het overzicht worden per groep van vaste activa afzonderlijk vermeld:

- de geaccumuleerde aanschaffingsprijzen of actuele waarden (in nieuwe staat):

- de afschrijvingen van het verslagjaar en de geaccumuleerde afschrijvingen;

- de verhoging (of verlaging) van de boekwaarde in het verslagjaar wegens herwaardering, voorzover herwaarderingen plaats vonden;

- de boekwaarde

21) Toelichring III artikel 10.9

22) Toelichting III artikel 10.10

29) Mr Th. S. IJsselmuiden, Wet op de Jaarekening, uitgave Kluwer, 1972; pag. 100.
} 
niet de economische levensduren te vermelden, maar gaf het volgende bevel: „De toelichting op de waardering van de duurzame produktiemiddelen dient tevens te vermelden, onderscheiden naar de groepen van produktiemiddelen:

- de investeringen in het verslagjaar;

- de vervangingswaarde respectievelijk aanschaffingskosten aan het einde van het verslagjaar;

- de afschrijvingen van het verslagjaar;

- de geaccumuleerde afschrijvingen per het einde van het verslagjaar;

- de wijziging van de boekwaarde in het verslagjaar wegens herwaardering;

- de boekwaarde."

Naar blijkt heeft de OK aan DE als verplichting opgelegd hetgeen het TO als aan. beveling schreef, met één uitbreiding, t.w. de investeringen (per groep) in het verslagjaar. Deze toevoeging lijkt mij zeer wel te passen in de Beschouwingen van het TO.

Bij DE maakten de vaste activa met $253 \mathrm{mln} 37 \%$ van de balanstelling uit. Hoe deze post zich verhoudt tot omzet of toegevoegde waarde is niet bekend, daar de winst- en verliesrekening van DE niet is gepubliceerd. De genoemde balansverhouding ligt echter in een orde van grootte, die wij bij vele ondernemingen aantreffen. Daaruit valt, zo meen ik, te concluderen dat het aan DE gegeven bevel toepasselijk is te achten voor alle ondernemingen, in wier balans de post vaste activa van enige betekenis is.

\section{Conclusie}

Tot gejuich zal deze eersteling geen aanleiding geven. Met het stilzwijgend voorbijgaan aan de Beschouwingen van het TO is aan belanghebbenden bij jaarreke. ningen immers geen dienst bewezen.

Het arrest gaat in zijn aanwijzingen aanmerkelijk verder dan de Beschouwin. gen en de commentatoren als vereisten beschreven. Voor die belanghebbenden die meenden dat het TO in zijn beschouwingen al rijkelijk ver ging, derhalve te minder reden tot juichen. Zij echter, die meenden dat het TO zich in zijn uitingen te vrijblijvend opstelde, lijken de $\mathrm{OK}$ aan hun zijde te vinden, hetgeen hun zoal geen gejuich dan toch een tevreden glimlach zal ontlokken. 